\title{
The relationship between blood lipid indicators and carcass traits and with the concentration of omega- 3 fatty acids in the longissimus dorsi muscle of growing pigs
}

\author{
S. Raj ${ }^{1,3}$, M. Sobol $^{1}$, G. Skiba', D. Weremko' and E. Poławska ${ }^{2}$ \\ ${ }^{1}$ The Kielanowski Institute of Animal Physiology and Nutrition, Polish Academy of Sciences \\ 05-110 Jabłonna, Poland \\ ${ }^{2}$ Institute of Genetics and Animal Breeding, Polish Academy of Sciences \\ Jastrzębiec, 05-552 Magdalenka, Poland
}

KEY WORDS: pigs, omega-3 fatty acids, blood lipid indicators

Received: 20 March 2014

Revised: 24 October 2014

Accepted: 28 November 2014

${ }^{3}$ Corresponding author: e-mail: s.raj@ifzz.pan.pl

\begin{abstract}
The relationship between blood lipid indicators, subcutaneous and intramuscular fat contents and with the concentration of omega- 3 fatty acids in the musculus longissimus dorsi (MLD) was investigated to search for biomarkers specifically associated with one of these relationships. The study was carried out on 32 gilts growing from 60 to $105 \mathrm{~kg}$ body weight (BW). The pigs were fed control $(\mathrm{C})$ or experimental diets ( $\mathrm{L}, \mathrm{M}$ and $\mathrm{H}$ ) in which $10 \%$ of metabolizable energy of diet $\mathrm{C}$ was replaced by $3.5 \%$ of fat mixtures that introduced in the different ratios of omega- 3 fatty acids into the diets. The pigs were slaughtered at $105 \mathrm{~kg} \mathrm{BW}$ and the serum concentrations of total protein (TP), triglycerides (TRIG), total cholesterol (CHOL), and high-, low-, and very low-density lipoproteins (HDL, LDL, VLDL, respectively) were determined. Backfat thickness, meat content in the carcass, and the fatty acid composition of MLD were estimated. Increased omega-3 fatty acid contents in the diet resulted in decreased concentrations of blood lipid indicators. TRIG displayed a significant correlation with meat content and backfat thickness in the carcass $(r=-0.54, P<0.01$ or $r=0.43, P<0.05$ ). Also, a significant correlation was found between TRIG in the blood and the concentration of eicosapentaenoic and docosapentaenoic acids in the MLD (average $r=-0.56, P<0.01$ ) and between CHOL in the blood and the concentration of linolenic acid in the MLD $(r=-0.61, P<0.01)$. Although the presented relationships were shown to be statistically significant, these blood lipid indicators should be viewed with caution as biomarkers specifically associated with carcass fatness.
\end{abstract}

\section{Introduction}

Lipid content and fatty acid (FA) composition are important factors in both the nutritional quality of meat and human health. It is well known that modern human diets are characterized by a higher content of saturated fatty acids, linoleic acid and linoleic/linolenic acid ratio than recommended by Amine et al. (2002).
Therefore, in dietary recommendations for humans it is often proposed to reduce the consumption of pork to lower the risk of cardiovascular disease (Willett et al., 1995). Other authors propose improving the health value of meat by changing the fatty acid profile of pig fat depots. An effective method of achieving this, thereby modifying the human diet, is changing the diet for pigs (Nguyen et al., 2003a; 
Raj et al., 2010; Kouba and Sellier, 2011; Wojtasik et al., 2012).

Among the different fatty acid groups, longchain omega-3 polyunsaturated fatty acids (LC omega-3 PUFA) are of particular interest due to their beneficial role in human health. In monogastric animals (pigs, poultry, ostrich) and humans, linoleic acid is an essential fatty acid, so it must be supplied in the diet and can subsequently be bioconverted to longer and more unsaturated long-chain omega- 6 and omega-3 PUFA. It should also be emphasized that humans and pigs can metabolize about onethird of consumed linolenic acid to eicosapentaenoic and docosapentaenoic acids, and less to docosahexaenoic acid, as well as linoleic to arachidonic acid, AA (e.g., Kloareg et al., 2007). Moreover it was found that as humans age, the activity of their enzymes (i.e. elongases, $\Delta 5$ and $\Delta 6$-desaturases) involved in the biosynthesis of docosapentaenoic and docosahexaenoic or arachidonic acids is decreased (Heird and Lapillonne, 2005). It seems that diets for pigs producing healthy meat should include longchain omega-3 PUFA since the linolenic acid as a precursor of long-chain omega-3 PUFA cannot be considered as the only source of EPA and DHA in the diet.

Recent studies have also shown that blood lipid indicators can be used as markers to assist in the selection for meat quality and, specifically, for the deposition of lipids and fatty acids (Gao et al., 2007; Cánovas et al., 2009). The concentrations of lipoproteins, cholesterol and triglycerides in the blood serum are the results of processes occurring in lipogenic tissues of the body under the influence of genetic and dietary factors (Cánovas et al., 2009). Determining these relationships can help understand the specific linolenic acid metabolic pathways of fat.

Only a few studies have examined the relationship between the concentration of lipid indicators in the blood with the fat content and FA profile in tissues (e.g., Muñoz et al., 2012). The results of this work show only a small relationship between the concentration of blood lipid indicators and the contents of saturated (SFA), monounsaturated (MUFA) and polyunsaturated fatty acids (PUFA) in tissues of pigs fed diets with different FA profiles. However, the relation between lipid blood indicators and FA profile in animal tissue when omega-3 PUFA was added to diet was not investigated.

Thus, the objective of the present study was to evaluate the relationship between selected indicators of the blood serum and the health parameters of the musculus longissimus dorsi and/or carcass fatness in pigs fed diets supplemented with different amounts of linolenic, eicosapentaenoic, docosapentaenoic and docosahexaenoic acids.

The observed relations could be used as potential biomarkers for indicating the carcass subcutaneous fat deposition and concentration of omega-3 in the meat.

\section{Material and methods}

\section{Animals}

The study was carried out on 32 crossbreed gilts [ $(0$ Duroc $\times \propto$ ( $\hat{O}$ Danish Landrace $\times$ q Polish Large White)] growing from 25 to $105 \mathrm{~kg}$ body weight (BW). The animals were free of genes responsible for meat defects. The origin of the pigs minimized their genetic variability as they were the offspring of one boar and eight sibling sows. The pigs were kept in individual pens $(1.2 \times 2.8 \mathrm{~m}$, concrete floor without straw) equipped with a nipple drinker and feeder, under thermo-neutral conditions: air temperature $18-20^{\circ} \mathrm{C}, 60 \%-70 \%$ humidity, $0.2-0.4 \mathrm{~m} \cdot \mathrm{s}^{-1}$ of draught. The concentrations of carbon dioxide, hydrogen sulphide and ammonia were in accordance with Polish law (Regulation of the Minister of Agriculture and Rural Development, 2003).

\section{Diet and feeding}

During growth from 25 to $60 \mathrm{~kg} \mathrm{BW}$, all of the animals were fed a commercial grower diet (13.2 ME MJ $\cdot \mathrm{kg}^{-1}$ and $8.2 \mathrm{~g} \cdot \mathrm{kg}^{-1}$ ileal digestible lysine). At $60 \mathrm{~kg} \mathrm{BW}$, the pigs were allotted to 4 groups (8 gilts each) and up to $105 \mathrm{~kg} \mathrm{BW}$ (by 51 days, on average) they were fed a control or experimental diet. The diets contained similar amounts of metabolizable energy (average 13.5 $\mathrm{ME} \mathrm{MJ} \cdot \mathrm{kg}^{-1}$ ) and standardized ileal digestible lysine (average $\left.7.4 \mathrm{~g} \cdot \mathrm{kg}^{-1}\right)$. Standardized ileal digestible amino acids were balanced and the lysine:energy ratio (Lys $\mathrm{g} \cdot \mathrm{MJ}^{-1} \mathrm{ME}$ ) equalled 0.55 (Degussa, 2001). The components, chemical composition and nutritive value of the diets are given in Table 1.

In the experimental diets (L, M and $\mathrm{H}$ ), approximately $10 \%$ of the metabolizable energy of diet $\mathrm{C}$ was replaced by $3.5 \%$ of fat mixtures that introduced the different ratios of omega-3 fatty acids into the diets. The fat mixtures contained, \%: rapeseed oil 1.0, fish oil 2.0 and lard 0.5 (diet L); rapeseed oil 2.5 and linseed oil 1.0 (diet M); rapeseed oil 1.0, linseed oil 2.3 and lard 0.2 (diet $\mathrm{H})$. The diets differed in the amounts of linolenic (C18:3 n-3, ALA, from 0.6 to $\left.8.5 \mathrm{~g} \cdot \mathrm{kg}^{-1}\right)$, eicosapentaenoic (C20:5 $\mathrm{n}-3$, EPA, from 0.00 to $\left.0.70 \mathrm{~g} \cdot \mathrm{kg}^{-1}\right)$, docosapen- 
Table 1. Composition and nutritive value of diets $\left(\mathrm{g} \cdot \mathrm{kg}^{-1}\right)$ fed to pigs from 60 to $105 \mathrm{~kg}$ body weight

\begin{tabular}{|c|c|c|c|c|}
\hline \multirow{2}{*}{ Indices } & \multicolumn{4}{|l|}{ Diet $^{1}$} \\
\hline & $\mathrm{C}$ & $L$ & M & $\mathrm{H}$ \\
\hline \multicolumn{5}{|l|}{ Ingredients } \\
\hline barley & 305 & 360 & 360 & 360 \\
\hline wheat & 300 & 360 & 360 & 360 \\
\hline maize & 250 & 100 & 100 & 100 \\
\hline rapeseed meal $(31 \%)$ & 40 & 40 & 40 & 40 \\
\hline soyabean meal (44\%) & 80 & 80 & 80 & 80 \\
\hline rapeseed oil & - & 10 & 25 & 10 \\
\hline linseed oil & - & - & 10 & 23 \\
\hline fish oil (cod) & - & 20 & - & - \\
\hline lard & - & 5 & - & 2 \\
\hline Premix ${ }^{2}$ & 25 & 25 & 25 & 25 \\
\hline \multicolumn{5}{|l|}{ Chemical composition } \\
\hline dry matter & 891 & 889 & 892 & 886 \\
\hline ash & 38 & 41 & 41 & 41 \\
\hline organic matter & 853 & 848 & 851 & 743 \\
\hline crude protein & 158 & 167 & 172 & 165 \\
\hline fat (ether extract) & 25 & 62 & 61 & 59 \\
\hline crude fibre & 34 & 43 & 40 & 43 \\
\hline starch & 490 & 453 & 460 & 450 \\
\hline sugar & 88 & 83 & 84 & 87 \\
\hline \multicolumn{5}{|l|}{ Nutritive value } \\
\hline digestible protein (determined) & 131 & 134 & 133 & 133 \\
\hline lysine ${ }^{3}$ & 7.4 & & & \\
\hline methionine ${ }^{3}$ & 2.63 & & & \\
\hline threonine ${ }^{3}$ & 5.00 & & & \\
\hline tryptophan ${ }^{3}$ & 1.31 & & & \\
\hline Metabolizable energy ${ }^{4}, \mathrm{MJ} \cdot \mathrm{kg}^{-1}$ & 13.35 & 13.50 & 13.50 & 13.45 \\
\hline Lys/ME, $g \cdot \mathrm{MJ}^{-1}$ & 0.55 & 0.55 & 0.55 & 0.55 \\
\hline \multicolumn{5}{|c|}{ 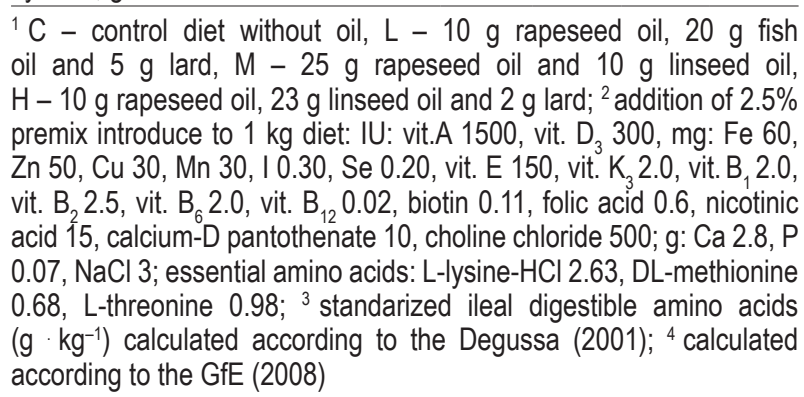 } \\
\hline
\end{tabular}

taenoic (C22:5 n-3, DPA, from 0.00 to $\left.0.12 \mathrm{~g} \cdot \mathrm{kg}^{-1}\right)$ and docosahexaenoic (C22:6 n-3, DHA, from 0.00 to $0.93 \mathrm{~g} \cdot \mathrm{kg}^{-1}$ ) acids (Table 2). The experimental diets contained $150 \mathrm{mg} \cdot \mathrm{kg}^{-1}$ of vitamin E to protect PUFAs against autoxidation.

Pigs were fed restrictively twice a day. Daily feed allowances were adjusted weekly after BW control. The apparent digestibility of energy and chemical ingredients of feeds were determined when the pigs reached approximately $80 \mathrm{~kg} \mathrm{BW}$, using the indicator method with $\mathrm{Cr}_{2} \mathrm{O}_{3}$ after a threeday faeces collection. The metabolizable energy of
Table 2. Content of fatty acids in diets $\left(\mathrm{g} \cdot \mathrm{kg}^{-1}\right)$ fed to pigs from 60 to $105 \mathrm{~kg}$ body weight

\begin{tabular}{lcccc}
\hline \multirow{2}{*}{ Fatty acids } & Diet $^{1}$ & & & \\
\cline { 2 - 5 } & \multicolumn{1}{l}{$\mathrm{C}$} & $\mathrm{L}$ & $\mathrm{M}$ & $\mathrm{H}$ \\
\hline Total fatty acids & 21.1 & 50.0 & 50.0 & 52.4 \\
SFA & 5.4 & 9.6 & 7.6 & 9.3 \\
MUFA & 6.2 & 16.7 & 17.4 & 15.1 \\
PUFA & 9.6 & 23.6 & 24.7 & 28.0 \\
PUFA/SFA & 1.8 & 2.5 & 3.3 & 3.0 \\
C16:0 & 4.6 & 7.2 & 5.9 & 6.9 \\
C16:1 & 0.07 & 0.78 & 0.08 & 0.22 \\
C18:0 & 0.6 & 1.3 & 1.0 & 1.8 \\
C18:1 & 5.6 & 14.0 & 16.7 & 14.0 \\
C18:2 n-6 & 8.8 & 19.6 & 19.6 & 19.3 \\
C18:3 n-3 & 0.60 & 2.3 & 5.1 & 8.5 \\
C20:4 n-6 & 0.09 & nd & nd & nd \\
C20:5 n-3 & nd & 0.70 & nd & 0.03 \\
C22:5 n-3 & nd & 0.12 & nd & 0.03 \\
C22:6 n-3 & 0.01 & 0.93 & nd & 0.15 \\
PUFA n-3 & 0.6 & 4.1 & 5.1 & 8.7 \\
PUFA n-6 & 8.9 & 19.6 & 19.6 & 19.3 \\
C18:2 n-6/C18:3 n-3 & 14.6 & 8.5 & 3.8 & 2.3 \\
PUFA n-6/n-3 & 8.9 & 4.8 & 3.8 & 2.2 \\
\hline
\end{tabular}

1 see Table 1; SFA - saturated fatty acids, MUFA - monounsaturated fatty acids, PUFA - polyunsaturated fatty acids (PUFA); nd - not determined

the diets was calculated based on digestible nutrient components, correcting for the digestible protein, fat, starch and simple sugar contents of the organic matter according to GfE (2008).

\section{Sample preparation}

The animals were electrically stunned then slaughtered at approximately $105 \mathrm{~kg} \mathrm{BW}$. Blood was drawn into clean tubes containing heparin and centrifuged $(10 \mathrm{~min}, 3500 \mathrm{rpm})$. The following biochemical indicators of blood serum were determined: total protein (TP), triglycerides (TRIG), total cholesterol (CHOL), and high-, low-, and very lowdensity lipoproteins (HDL, LDL, VLDL, respectively). The determinations were done on a VITROS DT 60 II System using diagnostic kits from ICN Instruments Poland Ltd.

The carcasses were chilled for $24 \mathrm{~h}$ at $4^{\circ} \mathrm{C}$ and then the entire musculus longissimus dorsi (MLD) was separated from the left half-carcass and weighed. The MLD was ground and a random sample of $500 \mathrm{~g}$ was taken and homogenized, packed into vacuum bags, frozen, and kept at $-40^{\circ} \mathrm{C}$ until analysis of ether extract and determination of fatty acid composition. 


\section{Chemical analysis}

The chemical composition of the diets, faeces and MLD was determined according to AOAC (2005) methods. Lipids of diets and MLD samples were extracted with chloroform-methanol $(2: 1)$ according to the method described by Folch et al. (1957). Fatty acid methyl esters were separated by gas chromatography on a GC-2010 AF Schimadzu gas chromatograph equipped with a $60 \mathrm{~m}$ capillary column (BPX70) having a $0.25 \mathrm{~mm}$ inner diameter and coating thickness of $0.25 \mathrm{~mm}$. The operating conditions were: helium was the carrier gas, the split ratio was $1: 100$, injector temperature $260^{\circ} \mathrm{C}$, detector temperature $260^{\circ} \mathrm{C}$, the initial column temperature $140^{\circ} \mathrm{C}$ was held for $1 \mathrm{~min}$, then increased to $200^{\circ} \mathrm{C}$ at a rate of $4^{\circ} \mathrm{C} \cdot \mathrm{min}^{-1}$, then increased to $220^{\circ} \mathrm{C}$ at a rate of $1^{\circ} \mathrm{C} \cdot \mathrm{min}^{-1}$. The total run time was $36 \mathrm{~min}$. Individual FA peaks were identified by comparison with a commercial standard, Supelco 37 Component FAME Mix. The concentration of fatty acids was expressed as a percentage of total FA in the investigated tissue.

\section{Statistical analysis}

Statistical analysis was performed using Statgraphics Centurion (2011) software. The effect of diets on the carcass characteristics of pigs was examined with one-way ANOVA. Differences between groups were tested using the Tukey test. Due to the close relation between the animals (litters) and the identical age of the pigs at slaughter, the influence of these factors was not included in the models. Mathematical relations between the content of linolenic acid in the diets and selected blood indicators at $105 \mathrm{~kg} \mathrm{BW}$ were expressed as a curvilinear model (exponential regression equation) according to the formula:

$$
\mathrm{Y}=\mathrm{a} \cdot \mathrm{X}^{\mathrm{b}}
$$

where: $\mathrm{Y}$ - concentration of selected blood indicators; $\mathrm{a}$ - intercept; $\mathrm{b}$ - slope ratio; $\mathrm{X}$ - content of linolenic acid in the diets $\left(\mathrm{g} \cdot \mathrm{kg}^{-1}\right)$. The relations between the blood lipid indicators at $105 \mathrm{~kg} \mathrm{BW}$ and carcass traits, as well as the concentrations (\%) of linolenic, eicosapentaenoic, docosapentaenoic, docosahexaenoic acids, and LA/ALA or PUFA/SFA ratios in the musculus longissimus dorsi were expressed as Pearson's correlations.

\section{Results}

The metabolizable energy concentration and digestible protein content were similar in all of the diets (average $13.5 \mathrm{MJ} \cdot \mathrm{kg}^{-1}$ and $133 \mathrm{~g} \cdot \mathrm{kg}^{-1}$, respectively; Table 1). Dietary fatty acid contents
Table 3. Performance and carcass characteristic of animals $(n=32)$

\begin{tabular}{lccccccc}
\hline \multirow{2}{*}{ Traits } & \multicolumn{1}{c}{ Diet $^{1}$} & & & & \multirow{2}{*}{ SEM } & $P$ \\
\cline { 2 - 7 } & $\mathrm{C}$ & $\mathrm{L}$ & $\mathrm{M}$ & $\mathrm{H}$ & & \\
\hline Days of fattening & 51.5 & 51.5 & 50.6 & 51.3 & 0.09 & $\mathrm{~ns}$ \\
Body weight, $\mathrm{kg}$ & 104 & 105 & 104 & 105 & 0.62 & $\mathrm{~ns}$ \\
Feed intake, $\mathrm{kg} \cdot$ day $^{-1}$ & 2.50 & 2.51 & 2.51 & 2.51 & 0.011 & $\mathrm{~ns}$ \\
Daily gain, g & 945 & 972 & 953 & 931 & 24 & $\mathrm{~ns}$ \\
FCR, kg feed $\cdot \mathrm{kg}^{-1}$ gain & 2.65 & 2.58 & 2.63 & 2.70 & 0.010 & $\mathrm{~ns}$ \\
Cold carcass, $\mathrm{kg}^{2.5}$ & 81.3 & 81.6 & 80.3 & 80.8 & 0.81 & $\mathrm{~ns}$ \\
Meat content, \% & 61.2 & 61.7 & 61.5 & 60.1 & 0.79 & $\mathrm{~ns}$ \\
Backfat thickness & , mm & 19.5 & 19.5 & 19.9 & 20.2 & 1.68 & $\mathrm{~ns}$ \\
\hline
\end{tabular}

${ }^{1}$ see Table $1 ;{ }^{2}$ backfat thickness - mean from 5 measurements (on the neck, over last thoracic vertebra and over beginning, middle and end of the muscle gluteus medius - on the cross); FCR - feed conversion ratio; ns - not significant

$\left(\mathrm{g} \cdot \mathrm{kg}^{-1}\right)$ are shown in Table 2 . In all groups of pigs, average daily feed intake, daily body weight gain, feed conversion ratio, carcass weight, meat content and backfat thickness were similar (Table 3).

\section{Blood lipid indicators}

Pigs fed diets enriched with different fat mixtures differed in the concentration of the blood lipid indicators compared with those fed the control diet (Table 4).

Increasing the linolenic acid content in the diet lowered the concentration of total protein by $8.0 \%(P<0.049)$, total triglycerides by $32.0 \%$ $(P<0.002)$, total cholesterol by $10.4 \%(P<0.05)$ and HDL-cholesterol by $17.3 \%(P<0.049)$ in the blood serum. There were no differences in the concentration of LDL-cholesterol, while increased intake of linolenic acid lowered the concentration of VLDLcholesterol by $36.8 \%(P<0.001)$. Supplementation of diet L with long-chain omega-3 PUFA slightly decreased the lipid indicators in blood plasma compared with diets $\mathrm{M}$ and $\mathrm{H}$.

Table 4. Concentration of blood lipid indicator in the pigs $(n=32)$

\begin{tabular}{cllllll}
\hline Indicator $^{1}$ & \multicolumn{2}{ll}{ Diet $^{2}$} & \multicolumn{5}{l}{} & SEM & $P$ \\
\cline { 2 - 6 } & $\mathrm{C}$ & $\mathrm{L}$ & $\mathrm{M}$ & $\mathrm{H}$ & & \\
\hline $\mathrm{TP}, \mathrm{g} \cdot \mathrm{l}^{-1}$ & $68.0^{\mathrm{b}}$ & $65.3^{\mathrm{b}}$ & $66.3^{\mathrm{b}}$ & $62.5^{\mathrm{a}}$ & 1.264 & 0.049 \\
$\mathrm{mmol} \cdot \mathrm{H}^{-1}$ & & & & & & \\
$\mathrm{TRIG}$ & $0.41^{\mathrm{A}}$ & $0.27^{\mathrm{B}}$ & $0.31^{\mathrm{B}}$ & $0.28^{\mathrm{B}}$ & 0.023 & 0.002 \\
$\mathrm{CHOL}$ & $2.31^{\mathrm{b}}$ & $2.14^{\mathrm{a}}$ & $2.19^{\mathrm{a}}$ & $2.07^{\mathrm{a}}$ & 0.157 & 0.050 \\
$\mathrm{HDL}$ & $1.04^{\mathrm{b}}$ & $0.90^{\mathrm{a}}$ & $0.90^{\mathrm{a}}$ & $0.86^{\mathrm{a}}$ & 0.082 & 0.049 \\
$\mathrm{LDL}$ & 1.08 & 1.12 & 1.15 & 1.08 & 0.091 & 0.087 \\
VLDL & $0.19^{\mathrm{b}}$ & $0.12^{\mathrm{a}}$ & $0.14^{\mathrm{a}}$ & $0.12^{\mathrm{a}}$ & 0.050 & 0.001 \\
\hline
\end{tabular}

${ }^{1} \mathrm{TP}$ - total protein, TRIG - total triglycerides, $\mathrm{CHOL}$ - total cholesterol, $\mathrm{HDL}$ - high-density lipoprotein, LDL - low-density lipoprotein, VLDL - very low-density lipoprotein; ${ }^{2}$ see Table 1 ; a,b means with different superscipts within a row are significantly different at $P \leq 0.05$; $A, B$ means with different superscripts within a row are significantly different at $P \leq 0.01$ 
Table 5. Relationship $\left(Y=a X^{b}\right)^{1}$ between the content of linolenic acid (ALA) in the diets $\left(\mathrm{g} \cdot \mathrm{kg}^{-1}\right.$ diet, $\left.\mathrm{X}\right)$ and concentration of blood indicators $(Y)$ in the pigs $(n=32)$

\begin{tabular}{llllll}
\hline $\begin{array}{l}\text { Blood } \\
\text { indicators } \\
\text { (Y) }\end{array}$ & $\mathrm{b}$ & $\begin{array}{l}\text { Content, } \\
\mathrm{g} \cdot \mathrm{kg}^{-1} \text { diet } r \\
(\mathrm{X})\end{array}$ & $P$ \\
\hline $\mathrm{TP}, \mathrm{g} \cdot \mathrm{l}^{-1}$ & $67.126 \pm 0.494$ & $-0.029 \pm 0.005$ & $\mathrm{ALA}$ & -0.97 & 0.001 \\
$\mathrm{mmol} \cdot \mathrm{l}^{-1}$ & & & & & \\
$\mathrm{TRIG}$ & $0.377 \pm 0.006$ & $-0.182 \pm 0.015$ & ALA & -0.98 & 0.006 \\
$\mathrm{CHOL}$ & $2.277 \pm 0.010$ & $-0.040 \pm 0.005$ & ALA & -0.95 & 0.006 \\
$\mathrm{HDL}$ & $0.990 \pm 0.020$ & $-0.069 \pm 0.005$ & ALA & -0.97 & 0.044 \\
$\mathrm{LDL}$ & $1.104 \pm 0.029$ & $-0.002 \pm 0.018$ & ALA & -0.27 & 0.740 \\
VLDL & $0.170 \pm 0.008$ & $-0.172 \pm 0.039$ & ALA & -0.97 & 0.048 \\
\hline
\end{tabular}

${ }^{1} \mathrm{Y}$ - concentration of selected blood indicators, $a$ - intercept, $b$ - slope ratio, $\mathrm{X}$ - content of linolenic acid in the diets; ${ }^{2}$ see Table 4

The relationships between linolenic acid content in the diets and the concentrations of total protein, triglycerides and cholesterol, and of HDL-, LDL- and VLDL-cholesterol in the blood serum are shown in Table 5. These relations are curvilinear and statistically significant for TP, TRIG, CHOL, HDL and VLDL. An increase the dietary ALA content by $1 \mathrm{~g}$ resulted in reduction of TP, TRIG, CHOL, HDL and VLDL by $-0.029,-0.182,-0.040,0.069$ and -0.172 $\mathrm{mmol} \cdot 1^{-1}$, respectively. The correlation coefficients for all measured indicators were similar and ranged from $r=-0.95$ for CHOL $(P<0.001)$ to $r=-0.98$ $(P<0.006)$ for TRIG. No relationships were found between the content of linolenic acid in the diets and the concentrations of LDL in the blood serum.

\section{The fatty acid concentrations in musculus longissimus dorsi}

The weight of the MLD did not differ among treatment groups (average $2.55 \mathrm{~kg}$ ), but content of the intramuscular fat in the $\mathrm{C}$ animals was lower than in the remaining groups $(2.9 \%$ vs average $3.25 \%$, difference non-significant; Table 6).

The concentrations of saturated fatty acids (SFA) and monounsaturated fatty acids (MUFA) were similar in all experimental groups (average $36.4 \%$ and $42.0 \%$, respectively), however, lower $(P<0.01)$ than in group C $(39.3 \%$ and $44.1 \%$, respectively). Concentrations of polyunsaturated fatty acids (PUFA) differed $(P<0.01)$ among groups and were the lowest in group C $(11.6 \%)$, higher in group L (13.9\%) and highest in groups $\mathrm{M}$ and $\mathrm{H}$ (average 15.1\%). The PUFA/SFA ratio was similar in all experimental groups, however, it was higher $(P<0.01)$ than in pigs from group $\mathrm{C}$ (average 0.40
Table 6. Weight of the musculus longissimus dorsi (MLD, kg), concentration (\%) of intramuscular fat (IMF) and SFA, MUFA, PUFA and particular fatty acids of pigs $(n=32)$

\begin{tabular}{|c|c|c|c|c|c|}
\hline \multirow{2}{*}{ Traits } & \multicolumn{4}{|l|}{ Diet $^{1}$} & \multirow{2}{*}{$\mathrm{SEM}^{3}$} \\
\hline & $\bar{C}$ & $\mathrm{~L}$ & $\mathrm{M}$ & $\mathrm{H}$ & \\
\hline MLD & 2.6 & 2.4 & 2.6 & 2.4 & 0.071 \\
\hline IMF & 2.9 & 3.4 & 3.1 & 3.3 & 0.351 \\
\hline \multicolumn{6}{|l|}{ Fatty acids ${ }^{2}$} \\
\hline SFA & $39.3^{B}$ & $36.4^{\mathrm{A}}$ & $35.4^{\mathrm{A}}$ & $37.5^{\mathrm{A}}$ & 0.480 \\
\hline MUFA & $44.1^{\mathrm{B}}$ & $42.2^{\mathrm{A}}$ & $42.1^{\mathrm{A}}$ & $41.8^{\mathrm{A}}$ & 0.460 \\
\hline PUFA & $11.6^{\mathrm{A}}$ & $13.9^{\mathrm{B}}$ & $14.9^{c}$ & $15.3^{C}$ & 0.431 \\
\hline PUFA/SFA & $0.29^{A}$ & $0.38^{\mathrm{B}}$ & $0.42^{\mathrm{B}}$ & $0.41^{\mathrm{B}}$ & 0.014 \\
\hline $18: 2 n-6$ & 10.1 & 10.6 & 11.2 & 10.1 & 0.376 \\
\hline $18: 3 n-3$ & $0.66^{\mathrm{A}}$ & $0.88^{\mathrm{A}}$ & $1.46^{\mathrm{B}}$ & $1.91^{\mathrm{C}}$ & 0.196 \\
\hline $20: 4 n-6$ & $0.43^{\mathrm{A}}$ & $0.76^{\mathrm{B}}$ & $0.70^{\mathrm{B}}$ & $0.74^{\mathrm{B}}$ & 0.033 \\
\hline $20: 5 n-3$ & $0.00^{\mathrm{A}}$ & $0.54^{\mathrm{B}}$ & $0.58^{\mathrm{B}}$ & $0.53^{B}$ & 0.094 \\
\hline $22: 5 n-3$ & $0.11^{\mathrm{A}}$ & $0.72^{\mathrm{B}}$ & $0.77^{\mathrm{B}}$ & $0.70^{\mathrm{B}}$ & 0.089 \\
\hline $22: 6 n-3$ & $0.14^{\mathrm{A}}$ & $0.42^{\mathrm{C}}$ & $0.35^{\mathrm{B}}$ & $0.32^{\mathrm{B}}$ & 0.047 \\
\hline PUFA n-6 & 10.5 & 11.3 & 11.9 & 10.8 & 0.387 \\
\hline PUFAn-3 & $0.91^{\mathrm{A}}$ & $2.56^{\mathrm{B}}$ & $3.16^{\mathrm{C}}$ & $3.46^{\mathrm{C}}$ & 0.141 \\
\hline $18: 2 n-6 / 18: 3 n-3$ & $15.3^{\mathrm{D}}$ & $12.0^{\mathrm{C}}$ & $7.7^{\mathrm{B}}$ & $5.3^{\mathrm{A}}$ & 0.546 \\
\hline PUFA n-6/n-3 & $11.6^{\mathrm{D}}$ & $4.4^{\mathrm{C}}$ & $3.8^{\mathrm{B}}$ & $3.1^{\mathrm{A}}$ & 0.153 \\
\hline
\end{tabular}

1 see Table 1; ${ }^{2}$ see Table 1; ${ }^{3}$ SEM - standard error of mean; $A, B, C, D$ means with different superscripts within a row are significantly different at $P \leq 0.01$

vs 0.29 , respectively). Concentrations of linoleic acid did not differ among groups (mean 10.5\%), but concentrations of linolenic acid differed significantly $(P<0.01)$ and were: $0.66 \%$ (group $C$ ), $0.88 \%$ (group L), $1.46 \%$ (group $\mathrm{M}$ ) and $1.91 \%$ (group H). The contents of AA, EPA and DPA in the experimental groups were similar (mean $0.73 \%, 0.55 \%$ and $0.73 \%$, respectively) but higher $(P<0.01)$ than in group $\mathrm{C}$ (mean $0.43 \%, 0.00 \%$ and $0.11 \%$, respectively). The concentration of DHA was the lowest $(P<0.01)$ in group $\mathrm{C}(0.14 \%)$, higher $(P<0.01)$ in groups $\mathrm{M}$ and $\mathrm{H}$ (average $0.33 \%)$ and the highest $(P<0.01)$ in group $\mathrm{L}(0.42 \%)$. The omega-6 PUFA concentration was similar in all groups (mean 11.14\%), whereas that of omega-3 PUFA differed $(P<0.01)$ among groups and equalled: $0.91 \%$ (group C), $2.56 \%$ (group L), 3.16\% (group $\mathrm{M})$ and $3.46 \%$ (group H). The ratio of $\mathrm{C} 18: 2 \mathrm{n}-6 /$ C18:3 n-3 differed $(P<0.01)$ and was the highest in group C (15.3), lower in group L (12.0), even lower in group $\mathrm{M}(7.7)$ and the lowest in group $\mathrm{H}$ (5.3). When the PUFA $n-6 / n-3$ ratio was compared among groups, however, it was found that this value was 11.6, 4.4, 3.8 and 3.1 for group $\mathrm{C}, \mathrm{L}, \mathrm{M}$ and $\mathrm{H}$, respectively. 
Table 7. Relationship $(r)$ between blood lipids indicators and carcass traits of pigs $(n=32)$

\begin{tabular}{|c|c|c|c|c|c|}
\hline \multirow[b]{2}{*}{$\begin{array}{l}\text { Blood lipid } \\
\text { indicators }{ }^{1}\end{array}$} & \multicolumn{5}{|c|}{ Carcass traits } \\
\hline & $\begin{array}{l}\text { carcass } \\
\text { weight, } \\
\mathrm{kg}\end{array}$ & $\begin{array}{l}\text { dressing } \\
\text { percentage, } \\
\%\end{array}$ & $\begin{array}{l}\text { backfat } \\
\text { thickness, } \\
\mathrm{mm}^{2}\end{array}$ & $\begin{array}{l}\text { meat in } \\
\text { the carcass, \% }\end{array}$ & $\begin{array}{l}\text { loin eye } \\
\text { area, } \\
\mathrm{mm}^{2}\end{array}$ \\
\hline $\mathrm{TP}, \mathrm{g} \cdot \mathrm{l}^{-1}$ & $0.40^{*}$ & 0.29 & 0.13 & $0.42^{*}$ & 0.11 \\
\hline \multicolumn{6}{|l|}{$\mathrm{mmol} \cdot \mathrm{l}^{-1}$} \\
\hline TRIG & -0.10 & 0.25 & $0.43^{*}$ & $-0.54^{* *}$ & -0.28 \\
\hline $\mathrm{CHOL}$ & 0.13 & $0.43^{*}$ & 0.17 & 0.15 & 0.09 \\
\hline HDL & 0.25 & -0.19 & 0.23 & -0.16 & 0.10 \\
\hline LDL & -0.22 & $0.53^{* *}$ & 0.05 & -0.21 & 0.04 \\
\hline VLDL & 0.10 & 0.25 & 0.33 & -0.04 & 0.17 \\
\hline
\end{tabular}

${ }^{1}$ see Table $4 ;{ }^{*} P<0.05,{ }^{* *} P<0.01$

\section{Relationship between blood lipid indicators and carcass traits}

The concentration of lipid indicators in the blood serum displayed a low correlation with carcass traits (Table 7). The serum TP concentration was positively correlated $(P<0.05)$ with carcass weight and meat content in the carcass $(r=0.40$ and $r=0.42$, respectively). However, TRIG concentrations were positively related with backfat thickness $(r=0.43, P<0.05)$ and negatively with meat content in the carcass $(r=-0.54, P<0.01)$. Also, a positive correlation was found between serum blood $\mathrm{CHOL}$ or LDL and dressing percentage ( $r=0.43$ or $r=0.53$, respectively).

\section{Relationship between blood lipid indicators and fatty acid concentrations in the musculus longissimus dorsi}

The relationships between blood lipid indicators and the concentration of intramuscular fat and fatty acids in the musculus longissimus dorsi are shown in Table 8. All of the relationships between blood lipid indicators and fatty acid concentrations and PUFA/ SFA ratios in the intramuscular fat were negative.

Table 8. Relationship $(r)$ between blood lipids indicators and concentration (\%) of IMF, ALA and LC n-3 PUFA in the musculus longissimus dorsi of pigs ( $\mathrm{n}=32$ )

\begin{tabular}{ccccccc}
\hline Blood lipid & \multicolumn{6}{c}{ Musculus longissimus dorsi $(\mathrm{n}=32)$} \\
\cline { 3 - 7 } indicators & IMF & ALA & EPA & DPA & DHA & LA/ALA PUFA/SFA \\
\hline $\mathrm{TP}, \mathrm{g} \cdot \mathrm{I}^{-1}$ & 0.14 & $-0.44^{*}-0.07$ & -0.07 & -0.03 & $0.38^{*}$ & -0.18 \\
$\mathrm{mmol} \cdot \mathrm{I}^{-1}$ & & & & & & \\
$\mathrm{TRG}$, & -0.22 & $-0.42^{*}-0.57^{* *}-0.56^{* *}-0.42^{*}$ & 0.20 & -0.27 \\
$\mathrm{CHOL}$ & -0.03 & $-0.61^{* *}-0.29$ & -0.30 & -0.26 & $0.46^{*}$ & $-0.48^{*}$ \\
$\mathrm{HDL}$ & -0.09 & $-0.46^{*}-0.30$ & -0.35 & -0.25 & 0.34 & -0.17 \\
$\mathrm{LDL}$ & 0.09 & $-0.43^{*}-0.01$ & -0.02 & -0.09 & 0.32 & -0.17 \\
$\mathrm{VLDL}$ & -0.11 & $-0.45^{*}-0.08$ & -0.07 & -0.06 & 0.25 & -0.22 \\
\hline
\end{tabular}

${ }^{1}$ see Table 4; IMF - intramuscular fat, ALA - linolenic acid, EPA - eicosapentaenoic acid, DPA - docosapentaenoic acid, DHA - docosahexaenoic acid; ${ }^{*} P<0.05,{ }^{* *} P<0.01$
The highest negative correlation was found between circulating total protein and concentration of linolenic acid $(r=-0.44, P<0.05)$. Moreover, circulating total protein showed a positive correlation with the LA/ALA ratio $(r=0.38, P<0.05)$. The correlations between the level of total triglycerides in the serum and the concentration of EPA and DPA in the intramuscular fat of the musculus longissimus dorsi were similar and higher than with linolenic acid and DHA (mean $r=-0.57 ; P<0.01$, vs $r=-0.42$, $P<0.05$, respectively) and with the PUFA/SFA ratio $(r=-0.27, P>0.05)$. The highest correlation of total serum cholesterol concentration was with linolenic acid $(r=-0.61, P<0.01)$. Moreover, a positive correlation between total serum cholesterol and the ratio of linoleic/linolenic acid $(r=0.46, P<0.05)$ and a negative correlation with the PUFA/SFA ratio $(r=-0.48, P<0.05)$ were found. A negative correlation was also found between circulating HDL, LDL and VLDL and the concentration of linolenic acid (mean $r=-0.45$, $P<0.05)$.

\section{Discussion}

According to our assumptions, replacing 10\% of metabolizable energy of the basal diet by different fat mixtures did not influence the performance or carcass traits of animals due to the same energetic and nutritive values and feeding regime. Our results are similar to the earlier studies presented by Nguyen et al. (2003a) and Mitchaothai et al. (2007). Admittedly, the muscle of pigs of the control group had less intramuscular fat than the experimental pigs, but this difference was insignificant. In contrast, Nguyen et al. (2003a) and Wojtasik et al. (2012) found no differences in the intramuscular fat of the MLD in animals fed similarly as ours.

Our study is one of the few demonstrating the hypolipidemic effect of moderate doses of linolenic acid or long-chain omega-3 PUFA in the diet on lipid blood serum indicators in pigs. We observed a reduction of TP, TRIG, CHOL and HDL in pig serum caused by supplementation of diets by oil mixtures containing linseed, rapeseed and fish oil. The addition of these oils to the diet had no effect on the plasma LDL-cholesterol level, however. Our results are in agreement with other studies showing that diets enriched in linolenic acid and long-chain omega-3 PUFA caused a reduction of TP, TRIG, CHOL and HDL in the blood serum (e.g., Więcek et al., 2010). However, only a few studies have tried to determine the relationship between the intake of linolenic acid or long-chain omega-3 PUFA and 
plasma lipid concentrations in pig serum. In our study we found a strong relationship between these parameters. We found that an increased intake of linolenic acid or long-chain omega-3 PUFA in the diet reduced the concentration of total triglycerides, total cholesterol and HDL-cholesterol in the blood plasma. Moreover, we found a strong curvilinear relationship between the content of linolenic acid in the diets and blood serum indicators. Other authors (e.g., Więcek et al., 2010) also found a beneficial effect of the concentration of long-chain omega-3 PUFA (from linseed) in feed on reducing the blood lipid concentration. However, these authors did not show the relations between the investigated parameters.

Our results are similar to those given by Yanovych et al. (2013). These researchers found that birds (geese) fed a diet containing fish oil had lower content of total triglycerides and cholesterol than those fed a diet containing soyabean oil. Similarly, Harris (1997) demonstrated that increasing the intake of long-chain omega-3 PUFA (mainly EPA and DHA) with food decreased the levels of total triglycerides in human blood serum. Sacks and Katan (2002) found that replacement of saturated or trans-unsaturated to monounsaturated or polyunsaturated fatty acids delivered from vegetable oils, reduced the total cholesterol and LDL cholesterol concentrations in serum. Contrary to our results, however, these authors found that increasing the amount of long-chain omega-3 PUFA (fish oil) in the diet decreased triglycerides, but had no effect on the LDL or HDL concentrations in the blood serum.

The different fat mixtures (linseed, rapeseed and fish oil) used in the diets did not influence the fat or total fatty acid contents in the musculus longissimus dorsi. As expected, however, they increased the concentration of long-chain omega-3 PUFA in the experimental diets and decreased SFA and MUFA. The beneficial effect of adding linseed oil, Camelina sativa oil, or fish oil to feed for other species (e.g., poultry) on the profile of animal tissues has also been demonstrated by other authors (Nguyen et al., 2003b; Jankowski et al., 2012; Pietras and Orczewska-Dudek, 2013). In our study, as the concentrations of ALA or LC omega-3 PUFA in the diets increased, the ratio of PUFA/SFA in the MLD increased, whereas the 18:2 n-6/18:3 n-3 and PUFA omega-6/omega-3 ratios decreased. Similar findings were presented by Duran-Montgé et al. (2010). Some researchers (Nguyen et al., 2003a; Kloareg et al., 2007; Duran-Montgé et al., 2010;
Raj et al., 2010; Wojtasik et al., 2012), however, pointed to a possibility of differences between intramuscular (e.g., in MLD) and subcutaneous fat in terms of the intensity with which their EPA, DPA and DHA contents increased, even though the concentrations of linoleic and linolenic acids were significantly higher in the subcutaneous than in intramuscular fat. Tissue differences in the content of linoleic and linolenic acids can be explained by the different levels of incorporation of these fatty acids into them. Based on a regression coefficient, Nguyen et al. (2003a) found that the efficiency of linoleic acid deposition is smaller for intramuscular fat than for adipose tissue. This indicates that linoleic acid is preferentially incorporated into adipose tissue. Another reason for such a response could be a difference in the content of intramuscular fat of MLD and subcutaneous fat. The latter tissue is characterized by a higher fat content, thus linoleic and linolenic acids can be more easily incorporated.

In our study, significant correlations between blood lipid indicators and some commercial traits were found; a negative correlation between TRIG and meat content and a positive one between TRIG and backfat thickness. However, Muñoz et al. (2012) found positive correlations between HDL concentrations and ultrasonically measured backfat thickness and a negative correlation between the protein content and ultrasonically recorded thickness of the loin of pigs fed a diet in which the MUFA and PUFA contents were increased at the expense of SFA. This response did not depend on the age of the pigs. In turn, Mersmann et al. (1982) found no differences between lean and obese pigs in serum lipid contents. Other researchers (e.g., Casellas et al., 2010) reported moderate estimates for heritability of serum lipid traits, thereby confirming that these traits may be altered by selection. Some authors (Etherton and Kris-Etherton, 1980) showed that plasma TRIG, very-low-density lipoprotein, and high-density lipoprotein were highly and positively correlated with production traits in one-year-old pigs. Although the concentration of HDL in the blood plasma of pigs is related to carcass fatness, the physiological cause for the relationship of HDL with backfat thickness and IMF is unclear (Taylor et al., 1992). It is known that that HDL plays an important role in the transport of cholesterol from peripheral tissues only to the liver. While VLDL, which circulates through the blood, gives up its triglycerides to the liver and then to adipose and muscle tissues until its residues are converted to LDL (e.g., Pond and Mersmann, 1996). 
Our results and the cited studies of other authors (Mersmann et al., 1982; Casellas et al., 2010; Muñoz et al., 2012) show that the relationships between blood lipid indicators and carcass fatness parameters are small. Thus, in the nearest future, blood lipid parameters cannot be markers for characteristics of the fat content of carcass tissues.

The present study demonstrates that inclusion of omega- 3 fatty acids into the standard pig diet alters the fatty acid composition of muscle to a greater degree than the concentration of indicators in the blood serum. Our results show that the concentration of total protein, triglycerides and lipid indicators in the serum displayed a low correlation with intramuscular fat of the MLD. Notwithstanding, the data showed highly negative relationships between all blood lipid indicators and linolenic acid concentrations in the intramuscular fat and between TRG in the blood and EPA, DPA and DHA concentrations in the MLD. Circulating lipid indicators were, however, weakly correlated with fatness traits. Similar findings were presented by Muñoz et al. (2012).

\section{Conclusions}

In conclusion, an increase in the content of linolenic acid and long-chain omega-3 polyunsaturated fatty acids in pig diets decreases blood lipid indicators and enables the production of pork with a favourable linoleic/linolenic ratio. The regression formula established on the basis of our results makes it possible to predict the content of linolenic acid in the intramuscular fat of musculus longissimus dorsi based on the concentration of some lipid indicators in the blood. The concentration of lipid indicators in the blood serum displayed a highly negative correlation with the content of omega-3 fatty acids in the intramuscular fat of musculus longissimus dorsi. These relationships were stronger than the correlation between blood lipid indicators and carcass fatness parameters.

Although the presented relationships were shown to be statistically significant, the defined blood lipid indicators should be taken with caution as biomarkers specifically associated with carcass fatness.

\section{Acknowledgements}

The study was supported in part by the European Regional Development Fund (Project No. POIG.01.01.02-014-090/09 'BIOFOOD-innovative, functional products of animal origin').

\section{References}

Amine E., Baba N., Belhadj M. et al., 2002. Diet, nutrition and the prevention of chronic diseases: report of a Joint WHO/FAO Expert Consultation, World Health Organization, Geneva (Switzerland)

AOAC, 2005. Association of Official Analytical Chemists, Official Methods of Analysis. $18^{\text {th }}$ Edition. Arlington, VA

Cánovas A., Quintanilla R., Gallardo D., Díaz I., Noguera J.L., Ramírez O., Pena R.N., 2009. Functional and association studies on the pig HMGCR gene, a cholesterol-synthesis limiting enzyme. Animal 4, 224-233

Casellas J., Noguera J.L., Reixach J., Diaz I., Amills M., Quintanilla R., 2010. Bayers factors analyses of heritability for serum and muscle lipid traitin Durock pigs. J. Anim. Sci. 88, 2246-2254

Degussa AG, 2001. Standardized lleal Digestibility of Amino Acids in Pigs. Frankfurt am Main (Germany)

Duran-Montgé P., Realini C.E., Barroeta A.C., Lizardo R.G., EsteveGarcia E., 2010. De novo fatty acid synthesis and balance of fatty acids of pigs fed different fat source. Livest. Sci. 132, 157-164

Etherton T.D., Kris-Etherton P.M., 1980. Characterization of plasma lipoprotein in swine with different propensities for obesity. Lipids 15, 823-829

Folch J., Lees M., Stanley G.H.S., 1957. A simple method for the isolation and purification of lipids from animal tissues. J. Biol. Chem. 22, 497-509

Gao Y., Zhang R., Hu X., Li N., 2007. Application of genomic technologies to the improvement of meat quality of farm animals. Meat Sci. 77, 36-45

GfE, 2008. Recommendation for the Supply of Energy and Nutrients to Pigs. DLG-Verlags-GmbH, Frankfurt am Main (Germany)

Harris W.S., 1997. n-3 fatty acids and serum lipoproteins: human studies. Amer. J. Clin. Nutr. 65, Suppl. 5, 1645S-1654S

Heird W.C., Lapillonne A., 2005. The role of essential fatty acids in development. Ann. Rev. Nutr. 25, 549-571

Jankowski J., Zduńczyk P., Mikulski D., Juśkiewicz J., Mikulska M., Zduńczyk Z., 2012. Effects of dietary soyabean, rapeseed and linseed oils on performance, slaughter yield and fatty acid profile of breast meat in turkeys. J. Anim. Feed Sci. 21, 143-156

Kloareg M., Noblet J., van Milgen J., 2007. Deposition of dietary fatty acids, de novo synthesis and anatomical partitioning of fatty acids in finishing pigs. Brit. J. Nutr. 97, 35-44

Kouba M., Sellier P., 2011. A review of the factors influencing the development of intermuscular adipose tissue in the growing pig. Meat Sci. 88, 213-220

Mersmann H.J., Pond W.G., Yen J.T., 1982. Plasma glucose, insulin and lipids during growth of genetically lean and obese swine. Growth 46, 189-198

Mitchaothai J., Yuangklang C., Wittayakun S., Vasupen K., Wongsutthavas Srenanul P., Hovenier R., Everts H., Beynen A.C., 2007. Effect of dietary fat type on meat quality and fatty acid composition of various tissues in growing-finishing swine. Meat Sci. 76, 95-101

Muñoz R., Tor M., Estany J., 2012. Relationship between blood lipid indicators and fat content and composition in Duroc pigs. Livest. Prod. 148, 95-102

Nguyen C.V., Smulikowska S., Mieczkowska A., 2003b. Effect of linseed and rapeseed or linseed and rapeseed oil on performance, slaughter yield and fatty acid deposition in edible parts of the carcass in broiler chickens. J. Anim. Feed Sci. 12, 271-288 
Nguyen L.Q., Nuijens M.C.G.A., Everts H., Salden N., Beynen A.C., 2003a. Mathematical relationship between the intake of $n-6$ and $n-3$ polyunsaturated fatty acids and their contents in adipose tissue of growing pigs. Meat Sci. 65, 1399-1406

Pietras M.P., Orczewska-Dudek S., 2013. The effect of dietary Camelina sativa oil on quality of broiler chicken meat. Ann. Anim. Sci. 13, 869-882

Pond W.C., Mersmann H.J., 1996. Genetically diverse pigs models for neonatal cholesterol nutrition: a review. Nutr. Res. 16, 707-721

Raj S., Poławska E., Skiba G., Weremko D., Fandrejewski H., Skomiał J., 2010. The influence of different fatty acids sources in diets on chemical composition of the body and utilisation of linoleic and linolenic acids in pigs. Anim. Sci. Pap. Rep. 28, 355-362

Regulation of the Ministry of Agriculture and Rural Development, 2003. Dz. U. no 167, pos. 1629 (in Polish)

Sacks F.M., Katan M., 2002. Randomized clinical trials on the effects of dietary fat and carbohydrate on plasma lipoproteins and cardiovascular disease. Amer. J. Med. 113, Suppl. 9B, 13S-24S
Statgraphics Centurion, 2011. Version XVI.I.

Taylor J.A., Salter D.N., Close W.H., Laswai G.H., 1992. Serum concentrations of insulin-like growth factor 1 and cholesterol in relation to protein and fat deposition in growing pigs. Anim. Prod. 55, 257-264

Więcek J., Rekiel A., Skomiał J., 2010. Effect of feeding level and linseed oil on some metabolic and hormonal parameters and on fatty acid profile of meat and fat in growing pigs. Arch. Anim. Nutr. 53, 37-49

Willett W.C., Sacks F., Trichopoulou A., Dresher G., Ferro-Luzzi A., Helsing E., Trichopoulos D., 1995. Mediterranean diet pyramid: a cultural model for healthy eating. Amer. J. Clin. Nutr. 61, 1402S-1406S

Wojtasik M., Raj St., Skiba G., Weremko D., Czauderna M., 2012. Effects of diets enriched in the omega-3 fatty acids on the carcass characteristic and fatty acid profile on intramuscular and subcutaneous fat in pigs. J. Anim. Feed Sci. 24, 635-642

Yanovych D., Czech A., Zasadna Z., 2013. The effect of dietary fish oil on lipid and fatty acid composition and oxidative stability of goose leg muscle. Ann. Anim. Sci. 13,155-165 